\title{
El espacio en Cien años de soledad: la interioridad como condición de la adivinanza del mundo
}

\author{
Bruno Cruz Petit ${ }^{1}$
}

Resumen. En este trabajo enfatizo el papel del espacio en la novela Cien años de soledad con la idea de que la dualidad espacio-tiempo está tan bien equilibrada como otras dicotomías que no solo articulan y realzan estéticamente el texto, sino que permiten desmenuzar el misterio de su significado. Me interesa señalar cómo, pese a que el libro tiene un carácter más narrativo que descriptivo, el espacio en general, y la casa de los Buendía en particular, son elementos que dan claves válidas para una interpretación de la que el propio escritor dio varios indicios. Indago por ello en las características del interior doméstico de la obra y las similitudes con la casa de los abuelos de Aracataca, de la que el autor esbozó un plano ${ }^{2}$ en 1978 que se reproduce en el artículo.

Palabras clave: Espacio en la literatura; Cien años de soledad; García Márquez; interioridad; Gilard.

\section{[en] Space in Cien años de soledad: Interiority as a Condition of the World's Revelation}

Abstract. In this work I emphasize the role of space in the novel Cien años de soledad with the idea that the space-time duality is equally balanced as other dichotomies that not only articulate and aesthetically enhance the text, but also allow us to unravel the mystery of its meaning. I am interested in pointing out how, although the book has a more narrative than descriptive character, the space in general, and the house of the Buendía in particular, are elements that give valid keys for an interpretation of which the writer himself gave several clues. I therefore inquire into the characteristics of the novel's domestic interior and the similarities with the grandparent's property at Aracataca (Colombia), whose plan (unpublished) was outlined by the author during a 1978 interview.

Keywords: Emilia Serrano de Wilson; Spanish-America; story; travel books; Semanario del Pacífico; Del cielo a la tierra.

Sumario: 1. La novela debía llamarse la casa. 2. El espacio mítico: dualidades, sueño, magia. 3. Los lugares soñados. 4. El espacio histórico: la casa cerrada. 5. El espacio biográfico: el cuarto de Melquíades.

Cómo citar: Cruz Petit, B. (2020) El espacio en Cien años de soledad: la interioridad como condición de la adivinanza del mundo, en Anales de Literatua Hispanoamericana 49, 205-217.

Cien años de soledad fue la gran novela que tuvo García Márquez en la mente desde su adolescencia, un reto descomunal por la ambición de la misma que sólo pudo concretarse merced al encierro de dieciocho meses de trabajo continuado en la Ciudad de México; un reto dado por la extensión en el tiempo narrativo, el número de personajes, la universalidad de los temas vinculados a las mitologías más arraigadas de la cultura, la mezcla de modernidad y tradición en el modo de contar una historia compleja que, sin embargo, todo tipo de lectores han podido leer de una manera apasionante y fluida. La prolífica producción crítica sobre su obra, lejos de ser un obstáculo para seguir escribiendo sobre ella, permite realizar nuevas interpretaciones que aprovechen y concilien aportes anteriores desarrollándolos a la luz de nuevos planteamientos como el

${ }^{2}$ Nota provisional: la publicación del plano que se adjunta está sujeta a la aprobación definitiva por parte del H. Ramson Center, de la Universidad de Texas en Austin, donde se encuentra el archivo García Márquez. La investigación que da lugar a este texto, patrocinada por la SRE de México y que tuvo lugar en Austin, no localizó una reproducción anterior de dicho plano, pero habría que corroborarlo con un especialista para acreditar completamente la primicia de publicación. 
análisis arquitectónico-literario que aquí se propone ${ }^{3}$. Además, para hacer más completa la aproximación espacial al texto vinculo el espacio de la novela con referencias al espacio que la inspiró, con lo que inevitablemente ésta es una lectura en clave psicobiográfica (Fernández 1981), que no entra en cuestiones estructuralistas, formalistas o intertextuales.

La creación espectacular de un mundo completo como es Macondo, con el mito de su fundación y destrucción, llevó a M. Vargas Llosa (1976) a poner el subtítulo de Historia de un deicidio a su análisis de la obra, en el que compara al escritor con el Dios de un universo creado a su imagen y semejanza. El carácter mítico de la historia de Macondo ha centrado gran parte de la voluminosa producción crítica deslumbrada por la brillante narración del génesis macondiano mágico y de un apocalipsis trágico, alimentada además por el respaldo extenso de lo que fue la recuperación del mito como tema por parte de la antropología, el estructuralismo y los estudios culturales del siglo XX. El espacio narrativo de la novela ha sido sobre todo un espacio mítico (Arnau 1975, Ludmer 1985) con una temporalidad protagonista en el análisis del mismo. Para Salazar Ramírez (1983: 47) Cien años de soledad puede ser vista como un tratado sobre la herencia, lo que es congruente con su carácter cíclico. E. Volkening (1998) describe el libro como un esfuerzo heroico por rescatar del olvido la historia. En este sentido, el episodio de la peste del insomnio es una metáfora del propósito inherente de la novela, una búsqueda proustiana del tiempo perdido, una lucha desesperada contra la amnesia general de la historia, clave en una recuperación crítica de la identidad latinoamericana muy presente en la segunda mitad del siglo XX.

Estamos, efectivamente, ante una novela universal, pero a la vez muy latinoamericana, muy anclada a un espacio-temporalidad concreta. La riqueza de la obra no sólo proviene de su fuerza narrativa y mítica sino del reflejo de una realidad que los lectores cercanos a la misma pudieron percibir desde un primer momento. $\mathrm{Si}$ bien es cierto que no hablamos de una obra con largas descripciones (como en el costumbrismo decimonónico latinoamericano), donde "el autor asume plenamente el lenguaje que históricamente ha correspondido a los mitos, es decir, la narración" (Maturo: 973, 113), pienso que son válidos un conjunto de análisis que llamo "realistas", en los que el espacio toma protagonismo ${ }^{4}$. El mismo García Márquez, al ser preguntado por M. Vargas Llosa (1967) sobre si se consideraba un escritor realista, fantástico o si creía que no se podía hacer la distinción respondió: "yo creo que particularmente en Cien años de soledad yo soy un escritor realista, porque creo que en América Latina todo es posible, todo es real". La respuesta contiene una ambigüedad significativa a la hora de aproximarnos a una literatura mágica, pero a la vez muy apegada a una experiencia propia, rica en sucesos que podrían parecer productos de la fantasía ${ }^{5}$. Los biógrafos del autor y él mismo, tanto en sus entrevistas como en su autobiografía Vivir para contarla, refuerzan la idea de que, en la génesis de Cien años de soledad está la propia vivencia del escritor en Aracataca. Cuando su amigo Plinio A. Mendoza le preguntó cuál había sido el propósito al sentarse a escribir, Cien años de soledad, GGM contestó: "Darle una salida literaria, integral, a todas las experiencias que de algún modo me hubieran afectado durante la infancia" (1982: 93).

Un elemento inspirador clave para encontrar dicha salida fue el recuerdo de la casa donde nació y se crió con sus abuelos: "partía de la obsesión que tengo yo por la casa de mi abuelo que me llevaba al circo" (García Márquez 1967: 67); "mi recuerdo más vivo y constante no es el de personas sino el de misma Aracataca donde vivían mis abuelos. Es un sueño recurrente que todavía persiste. Más aún: todos los días de mi vida despierto con la impresión, falsa o real, de que he soñado que estoy en esa casa" (Mendoza, García Márquez 1982: 19).

${ }^{3}$ Tuna Ultav (et. al. 2015: 134) usa el término análisis arquitectónico-literario para describir una metodología de investigación que saca a relucir las claves espaciales de textos literarios, mediante descripciones de escenarios de las novelas analizables con conceptos provenientes de la crítica arquitectónica.

${ }^{4}$ En América Latina la novela realista dio a la descripción de lugares, paisajes, aldeas, casas, un papel importante en la valorización de las identidades autóctonas. La apropiación simbólica del territorio en la era poscolonial prosiguió con la generación del boom latinoamericano, en la que se saca partido estético de las connotaciones y vínculos entre espacio y memoria colectiva. Para Diana Morán (1988: 83) la obra no es una novela mítica, sino que estamos ante "el trabajo de un escritor situado en el espacio y el tiempo". Para Morán, Macondo y la casa pueden verse como un juego de muñecas rusas, una superposición de aislamientos a los que se impone, desde la llegada de un gobernador foráneo, una modernidad disruptiva. Me parece interesante cómo esta autora aborda la dialéctica espacio-tiempo al señalar el aislamiento de los actores, paralelo al de la casa y la aldea, dentro de su tiempo subjetivo, con sucesivos encierros, voluntarios o impuestos; aunque no comparto el sentido general que le confiere al libro, la autosegregación trágica de la familia de la historia ("Macondo encerrado en un cerco, el del atraso latinoamericano", Moran 1988: 84) sino que veo en encierro como rito de iniciación y purificación para poder acceder a una verdad, inevitablemente trágica.

5 “Cuando llegué a Barranquilla (...) -cuenta GGM- había un problema con la toponímia (de la novela). Si hablaba de Aracata, Santa Marta...no me lo iba a creer; para que me creyeran había que inventar nombres que dieran una dimensión mítica a los pueblos y ciudades. Había que mitologizar. Creo que fue una aportación clave". Muchos críticos ven en el libro una parábola o alegoría de la historia de la humanidad, comenta Mendoza (1982). Y responde el novelista: "No, quise solo dejar una constancia poética del mundo de mi infancia (...)". 


\section{La novela debía llamarse la casa}

El viaje a Aracataca en febrero de 1950 fue seminal para la concepción de lo que acabaría siendo su obra maestra. GGM acompañó a su madre al pueblo de la infancia para tratar de vender la casa de los abuelos, entonces ocupada por inquilinos, pero visiblemente desmejorada, hecho que, junto al mismo hecho del reencuentro con los espacios de su infancia, debió causar un fuerte impacto en el joven Gabo. Sin embargo, Eligio García Márquez (2001) comenta que la mayoría de las primeras narraciones que haría su hermano sobre dicho viaje, versaban sobre todo sobre el pueblo fantasmal, las calles desoladas, el reencuentro con algunos habitantes...pero no sobre la casa (García 2002: 231), quizás debido a algún tipo de bloqueo emocional. En apoyo a esta idea estaría el hecho de que en 1976 el novelista colombiano se explayó con Vargas Llosa con la narración, no tanto del espacio de la casa, como del reencuentro de su madre con una amiga en la botica de la esquina, del abrazo y las lágrimas que presenció, los cuales lo dejaron conmocionado; en ese momento "[...] surgió la idea de contar por escrito todo el pasado de ese episodio [...]. A los 17 empecé (...). "Necesité cuatro libros para aprender a escribir Cien años de soledad (1976: 28)". "Escribí un primer párrafo que es el mismo primer párrafo que hay en Cien años de soledad... (cita de entrevista con V. Llosa en Oviedo, 1969: 88). El abandono en Barranquilla del borrador de una novela que debía llamarse La casa pudo deberse no sólo a la dificultad técnica que ha comentado GGM sino también a una necesidad de madurar emocionalmente para enfrentarse con recuerdos trascendentales en la constitución de su personalidad. A finales de 1950 inicia la que sería su primera publicación, La Hojarasca (que se imprimió en 1955), donde aparece por primera vez en su obra el pueblo de Macondo, aunque el proyecto de La casa no fue completamente abandonado en esos años ${ }^{6}$.

La palabra "casa" aparece en numerosos títulos de la literatura de esos años, lo que sugiere, según E. García (2001: 238), que el tema era una obsesión generacional. J. Cortázar publicaría su cuento la Casa tomada en 1947. W. Faulkner publicó en 1959 la Mansión, tras haber pensado y desechado como título la Casa oscura (The Dark House) para sus dos novelas precedentes. También era un tema que interesaba no sólo a novelistas y arquitectos sino a los filósofos. En 1954 M. Heidegger leía ante una audiencia de arquitectos alemanes su conferencia Construir, Habitar, Pensar, en la que advertía sobre el peligro de pérdida de los valores existenciales de la habitabilidad en la arquitectura funcionalista de la reconstrucción durante la posguerra. La influencia ulterior del existencialismo en la teoría de la arquitectura no se tardó en manifestarse; respondía a la falta de autenticidad en el habitar el mundo moderno ${ }^{7}$. G. Bachelard, con su Poética del espacio de 1957, año en que García Márquez está en Europa, consagró la aproximación humanística y fenomenológica al estudio de la casa, una respuesta a la idea funcionalista y positivista de espacio que se estaba diseminando en el mundo a medida que se democratizaba el acceso a la propiedad en la segunda mitad del siglo XX.

En el contexto intelectual anteriormente esbozado GGM fue madurando internamente su proyecto de gran novela sobre Macondo. Ya viviendo en México, en 1966, nos cuenta Gerald Martin (2009: 339) que el escritor se dio cuenta que "en lugar de escribir un libro sobre su infancia debía escribir un libro sobre los recuerdos de su infancia; no sobre la realidad sino sobre la representación de dicha realidad"; en términos fenomenológicos, no sobre la cosa en sí, sino cómo ésta es percibida, no sobre la casa o la familia sino sobre lo que memoria y la imaginación creó con dichos elementos. Lo anterior justifica, a mi juicio, la pertinencia del vínculo entre el pensamiento fenomenológico de Gastón Bachelard y Cien años de soledad. PalenciaRoth menciona puntualmente a Bachelard (1983: 120); el vínculo está muy bien expuesto por A. Noujoumian (2006) y figura en el artículo de F. Sanabria (2012) derivado de la ponencia presentada en el Congreso-celebración del 50 aniversario de la muerte del pensador francés. El texto recurre al autor francés para fundamentar una crítica sobre reconstrucción polémica y conversión en museo de la casa natal de GGM en Aracataca, al tomar el gobierno colombiano la decisión de demoler los pocos restos que quedaban para edificar un proyecto de casa-museo costosísimo para los parámetros de inversión y riqueza del pueblo; el

\footnotetext{
${ }^{6}$ Además de cuentos inspirados en la visita a Aracata como La siesta del martes, en Barranquilla publicó el cuento La casa de los Buendía (1950) en la revista Crónica, con el subtítulo de Apuntes para una novela. Eligio García Márquez destaca como posible influencia el poema de Rojas Herazo La casa entre los robles, integrado en la colección de poemas de 1952 El rostro de la soledad y calurosamente elogiado por su hermano en la columna "La Jirafa".

${ }^{7}$ D. Spurr (2012) sostiene que el encuentro de la literatura con el entorno doméstico es esencial en la definición de lo que se ha llamado Modernidad, y avanza como hipótesis que una posible crisis a finales del siglo XIX tanto de la literatura como del interior doméstico se manifiesta en la estética de la ruina y en el retiro hacia la interioridad existencial.
} 
escritor aprobó el diseño de la planta, como testimonia el plano de la casa firmado que D. Saldívar (2016) mostró, con la leyenda "consto que así fue".

A mi juicio, hay mucho recorrido para profundizar en el estudio fenomenológico del espacio en Cien años de soledad. Este enfoque nos enriquece una reflexión interesante sobre la interioridad espacial característica del habitar en la casa de los Buendía, con los sucesivos encierros que en ella veremos y el destacado papel del cuarto Melquíades, el de los pergaminos que contienen el misterio del destino de los protagonistas y de la novela. El núcleo de la presente interpretación proviene de la afirmación que GGM hizo en una entrevista a J. Gilard de que nunca imaginó el papel creciente que adquiría Melquíades en el transcurso de la escritura de la novela ("porque realmente está fuera de mi mitología personal"), lo que nos lleva a pensar que quizás ahí estén algunos de los demonios inconscientes del autor que se proyectan en su escritura.

En el análisis que propongo a continuación del espacio de Cien años de soledad (usaré la $29^{\circ}$ edición de 1972) señalo que podemos detectar tres espacialidades que se suceden en la novela: la mítica, la histórica y la biográfica. Derivo esta tipología de la tríada que propone Óscar Collazos (1983: 126-150) al estudiar las distintas temporalidades de la obra. Propongo que hay un espacio mítico (la casa tradicional, abierta al paisaje paradisíaco inicial), un espacio histórico (la casa ampliada y cerrada, aburguesada) y un espacio biográfico (el cuarto de los pergaminos de Melquíades, donde está escrito el final de la historia que está creando García Márquez).

\section{El espacio mítico: dualidades, sueño, magia}

El pensamiento mítico abunda en el desarrollo de dualidades que estructuran los relatos, así como explicaciones que eluden la racionalidad científica en beneficio de una verdad poética. Cien años de soledad presenta estas características desde los primeros párrafos, que además nos dan una clave interesante el manejo de la dialéctica espacio-tiempo que recorre el texto. El primer capítulo arranca con la famosa frase inicial se reescribió gracias a una intuición repentina de GGM mientras conducía su coche Opel blanco hacia Acapulco y que lo desbloqueó en la elaboración del texto. Ilustra, en este punto, el carácter de todo el libro. La primera frase tiene que ver con la temporalidad, extendida en el tiempo ("muchos años después", "tarde remota"), con dos hechos con un cargado peso emocional (un presunto fusilamiento, el recuerdo de ir a conocer el hielo acompañado por el padre) y la importancia del recuerdo, la recuperación del tiempo a través de la memoria ${ }^{8}$.

La segunda frase ("Macondo era entonces una aldea de veinte casas de barro y cañabrava construidas a la orilla de un río de aguas diáfanas...") sitúa la acción en el espacio ${ }^{9}$, la segunda dimensión de la novela, en este caso un paisaje paradisíaco, un "cosmos fundado" (Elíade 1998: 28) opuesto a lo que será un exterior ignoto, la "región encantada". En la tercera oración, que conecta el rasgo del mundo creado ("era tan reciente...") con lo que las personas hacían (señalar con el dedo las cosas, pues carecían de nombre) ya estamos de lleno en el espacio-tiempo (la historia de una familia extendida en el periodo de vida de una aldea) que va a estructurar y dar unidad a una narración compleja y barroca por la profusión de personajes, sensaciones, episodios. El primero de ellos, la llegada de una familia de gitanos entre los cuales está el gitano Melquíades. "Las cosas tienen vida propia", es su frase mágica inicial que conecta con la credulidad de los aldeanos, como José Arcadio Buendía, el patriarca fundador, quien imagina la aplicación de los imanes de Melquíades para sus propósitos de alquimista aficionado ante Úrsula, quien trata de disuadirlo, preocupada por mantener el "desmedrado patrimonio doméstico"; "muy pronto ha de sobrarnos oro para empedrar la casa", es la respuesta de José Arcadio Buendía. Pensamiento mágico y sentido común tradicional colisionan en el momento de la primera mención de la casa de los Buendía (la más grande del pueblo), que se erige en centro del cosmos macondiano, su umbilicus mundi.

\footnotetext{
${ }^{8}$ Para R. Williams (2010: 43) en dicha frase están tanto el presente, como el pasado y el futuro lo que señala la importancia de la problemática del tiempo en la trama y establece una concomitancia con el final, cuando los distintos tiempos se condensan en uno solo.

${ }^{9}$ Las descripciones de Macondo, al igual que las de la casa, son breves. Vamos conociendo la aldea gracias a la acumulación de descripciones puntuales, siempre vinculadas a lo que allí pasa, lo que irá formando en la mente del lector una imagen de la aldea. Ésta es una de las grandes virtudes de la novela, la capacidad de provocar en el lector, a la manera de los pintores impresionistas, la recreación de un mundo (incluso creación o evocación, según lo próximos que estemos a las referencias culturales implicadas) a partir de pequeñas y precisas pinceladas. Si en el proceso de escritura GGM fue del espacio (su visita a la casa, la memoria materializada) al tiempo (con el recuerdo de su abuelo acompañándolo al circo transformado en el descubrimiento del hielo), el de lectura es inverso: de la temporalidad vamos al espacio.
} 
La descripción de la casa se halla en la página 15; una sola frase es suficiente para darnos la idea del tipo de morada que alberga a la familia, la cual adopta una forma arquetípica (siendo el arquetipo un elemento común en los mitos): tradicional, digna, alegre, no lujosa pero completa. Está claramente inspirada en la primera vivienda construida por los abuelos de GGM, tras mudarse a Aracataca y comprar el predio con un pequeño habitáculo:

Tenía una salita amplia y bien iluminada, un comedor en forma de terraza con flores de colores alegres, dos dormitorios, un patio con un castaño gigantesco, un huerto bien plantado y un corral donde vivían en comunidad pacífica los chivos, los cerdos y las gallinas (15).

La descripción se completa en la página siguiente, con una a las consecuencias sensoriales-emocionales que se incrustan en el recuerdo (el olor):

Gracias a ella (Úrsula), los pisos de tierra golpeada, los muros de barro sin encalar, los rústicos muebles de madera construidos por ellos mismos estaban siempre limpios, y los viejos arcones donde se guardaba la ropa exhalaban un tibio olor de albahaca (16).

Se establece en estas primeras páginas una primera dualidad central, al presentarse los arquetipos de género asociados al reparto de esferas espaciales tradicional desde los tiempos neolíticos: el femenino en la esfera privada-doméstica (con Úrsula de sostén del hogar) y el masculino en la pública (José Arcardio Buendía, el patriarca que gobierna la esfera pública; realiza el trazado de las calles, explora las rutas de conexión con otras regiones). Sobre la posible asimetría de dicho reparto, me inclino en este punto a cuestionar el supuesto rol subordinado que GGM da a las mujeres y a coincidir con Mario A. Arango en que el autor hace de las mujeres personales centrales (cit. en Escandón 2011: 29), al mismo nivel que los hombres; no sólo por la lógica binaria que tiene el relato ${ }^{10}$, sino por el nivel de detalle con el que se describe la vida del hogar de los Buendía, derivado de un conocimiento del interior doméstico que tuvo el escritor desde su infancia (no en vano afirmó el escritor: "siempre he tenido la impresión de entenderme mejor con las mujeres [...]1982: 30,98). Úrsula sostiene el mundo de los Buendía a través de la casa, ya que "la casa en la vida del hombre suplanta contingencias, multiplica sus consejos de continuidad. Sin ella el hombre sería un ser disperso" (Bacherlard 2000: 30). La unidad de la novela tiene también que ver con dicha idea. Pese a la proliferación barroca de ramas genealógicas y personajes, hay una continuidad lograda no sólo con la aparición de patrones cíclicos de comportamiento de los distintos personajes o los temas transversales, sino por el papel de la casa, incluso una vez fallecida Úrsula ${ }^{11}$.

La incursión de la escritura en las distintas esferas o capas espaciales no termina en la casa. En ella José Arcadio Buendía, como harán los demás hombres de la familia, pasa "largas horas en su cuarto" (11). Durante los meses de lluvia se encierra en un pequeño cuarto construido en el fondo de la casa "para que nadie perturbara sus experimentos" en su espacio de alquimista ${ }^{12}$. El cuarto de la alquimia (posteriormente transformado en el taller de platería, concomitante al cuarto de los pergaminos: cuarto de la imaginación, la memoria y la creación) es un espacio mítico en cuanto participa del pensamiento pre-científico; será un elemento central de la novela porque es también el espacio de ensimismamiento, de iniciación ${ }^{13}$ ritual que llevará al último de los Aurelianos encerrados al descubrimiento de la profecía. El costo del encierro es una

${ }^{10}$ Para Escandón (2011: 24) "el concepto de matriarca que aparece en Cien años de soledad es el de una mujer como cabeza de una familia" (...), con un "poder restringido al hogar" que no puede evitar la hecatombe final provocada por el patriarcado. Pese a ello, creo que el reparto de esferas se corresponde con cierto equilibrio jerárquico que conectaría con las ideas sobre el género de I. Illich (1990). Además, como si de un equilibrio ying-yang se tratase, hay varias páginas en el relato en que tanto mujeres como hombres se erigen en protagonistas de los ámbitos opuestos. Úrsula interfiere en el ámbito público, en un primer momento sin lograr su objetivo (143) pero en otros momentos se impone: a su hijo cuando se trata de la vida del general, del mismo modo en que lo hace con A. Segundo (con lo que queda sugerido que el poder público es una concesión femenina al capricho masculino). En la esfera doméstico se ubican varios episodios interesantes en el sentido inverso, el de un control masculino: un fallido intento por empapelar la casa con billetes de peso (puesto que Úrsula la acaba repintando de blanco, 171), cuando A. Segundo decora la habitación de Meme (319) o al final del Diluvio, cuando arroja y destroza los objetos de la casa.

${ }^{11}$ Dice G. Márquez (1982: 100): “(...) ella (Úrsula) debía morir antes de la guerra civil, cuando se acercaba a los cien años de edad. Pero descubrí que si se moría el libro se derrumbaba. Cuando muere, ya el libro tiene tanto vapor que no importa lo que ocurra después”.

${ }^{12}$ La intimidad de la sustancia es un tema que Bachelard nombra, retomando al Jung de Psychologie und Alchemie para hablar de lo superlativo de lo oculto; es el misterio de la materia (que se repite en el recuerdo del hielo y los sueños de espejos y vidrios, superficies reflejantes donde el observador se observa a sí mismo tratando de entender el mundo). 
soledad que es también alejamiento matrimonial y familiar (la soledad proviene de la incapacidad de amar, dice GGM en Mendoza 1982: 97):

Con el pretexto de que el dormitorio nupcial estaba a merced de las polillas a pesar de la destrucción de las apetitosas muñecas de Remedios, (Aureliano Buendìa) colgó una hamaca en el taller, y entonces lo abandonó solamente para ir al patio a hacer sus necesidades (230).

Así, si en las primeras páginas ha quedado clara la división de género de los espacios, con los sucesivos encierros de los personajes se superpone a dicha dicotomía otra que es la del aislamiento-convivencia. En este punto cabe retomar el comentario de D. Saldívar sobre el único cambio que él advierte entre la forma de la casa de los Buendía y la de los Márquez en Aracataca; la ubicación de los espacios masculinos, que en la casa original se ubicaban, no en un lugar lejano, sino en el primer espacio a la izquierda de la fachada (la oficina del coronel) o, en el caso del taller de platería, como segundo cuarto en la enfilade contigua al corredor de las begonias, después del cuarto de invitados. Pudiera ser que el escritor tuviera en mente el cobertizo-taller de carpintería, que sí estaba al lado del patio. Pero otra hipótesis sería que, alejando al taller del resto de cuartos, GGM estaría reforzando la idea de soledad y aislamiento que recorre la novela, muy presente en los personajes masculinos (José Arcadio, Aureliano Buendía y el último Aureliano) y en algunos femeninos (Amaranta, Rebeca) ${ }^{14}$. El escritor mismo estaría aquí poetizando el espacio de un modo muy bachelardiano (la imaginación poética transforma los recuerdos y radicaliza dicotomías, recurriendo a arquetipos anclados en la tradición).

La ubicación del laboratorio de alquimia, estancia a medio camino entre la ciencia y la locura, junto al patio no es casual. José Arcadio Buendía "permaneció noches enteras en el patio vigilando el curso de los astros", allí "le construyeron un cobertizo de palma para protegerlo del sol y la lluvia" (76) y allí morirá atado al castaño ${ }^{15}$. También Aureliano Buendía morirá en el patio y de él Rebeca tomará tierra para comer en sus momentos de regresión a la demencia. El patio también es un lugar impregnado de espiritualidad, un lugar trágico de apertura al cielo, con un axis mundi conector de niveles cósmicos: el árbol. Un elemento vertical que contrasta con la horizontalidad terrenal de la huerta, donde Úrsula y los niños cultivan el plátano y la malanga, la yuca y el ñame, mientras el marido cae progresivamente en "un estado de delirio perpetuo del cual no se volvería a recuperar" (74).

\section{Los lugares soñados}

Además de las dualidades, en los mitos encontramos frecuentes sueños, premonitorios de un destino o portadores de significados. Para G. Bachelard $(2000,30)$ la casa permite que soñemos en paz y, a su vez, los recuerdos de las distintas moradas de nuestra vida se compenetran en el sueño. El espacio soñado de la novela, con casas de materiales insólitos y cuartos infinitos, es un leitmotiv que recorre el texto. Aparece por primera vez como parte del mito fundacional de Macondo en el sueño de José Arcadio Buendía:

José Arcadio Buendía soñó esa noche que en aquel lugar se levantaba una ciudad ruidosa con casas de paredes de espejo. Preguntó qué ciudad era aquella, y le contestaron con un nombre que nunca había oído, que no tenía significado alguno, pero que tuvo en el sueño una resonancia sobrenatural: Macondo. Al día siguiente convenció a sus hombres de que nunca encontrarían el mar. Les ordenó

\footnotetext{
${ }^{14}$ En la entrevista con V. Llosa de 1966, el autor peruano señala el aspecto paradójico de la palabra soledad en un título de una novela 1lena de personajes, con una casa caribeña permanente poblada, a lo que GGM contesta que "si logro explicármelo, quizás ya sea totalmente racional y ya no me siga preocupando". En entrevista con González Bermejo (1971: 27) el autor señaló que nadie había reparado que lo que realmente le interesaba en el libro fue la idea de la soledad, opuesta a la solidaridad y esencia del libro. "La frustración de Macondo procede de ahí. De la falta de amor". Esta idea ha sido enfatizada por G. Martin, Browitt y S.Minta. Michael Bell retomó la idea para el titular de su libro GM: Solitude and Solidarity (1993).

15 "Entonces fue al castaño, pensando en el circo, y mientras orinaba trató de seguir pensando en el circo, pero ya no encontró el recuerdo, 234 ". La inclusión del hecho de orinar en un momento trascendente y en el espacio sagrado alrededor del castaño pudiera sorprendernos como le pasó a Fray Ramón Pané con los taínos de la isla Española que "tiraron las imágenes (cristianas) al suelo y las cubrieron de' tierra y después orinaron encima" (1988: 53), hecho que en realidad correspondía, como apunta J.J. Arrom en las notas, a un "rito agrícola en el cual solían enterrar en sus labranzas una representación lítica de Yúcahu Bagua Maórocoti para que fecundase las siembras” (1988: 81). R. Cassá (1974: 170) confirma "la interrelación mágica de los ídolos propiciatorios agrícolas pétreos y la idea animista de la fertilidad del falo" en la tradición de una civilización precolombina cuyos orígenes, en la cuenca del Orinoco, no están lejanos al Caribe colombiano donde creció GGM.
} 
derribar los árboles para hacer un claro junto al río, en el lugar más fresco de la orilla, y allí fundaron la aldea (28) [...]. José Arcadio Buendía no logró descifrar el sueño de las casas con paredes de espejos hasta el día en que conoció el hielo. Entonces creyó entender su profundo significado. Pensó que en un futuro próximo podrían fabricarse bloques de hielo en gran escala, a partir de un material tan cotidiano como el agua, y construir con ellos las nuevas casas de la aldea.

Es interesante ver cómo los sueños de la novela se van conectando entre sí y alimentando de imágenes inquietantes, con materiales constructivos imposibles o lejanos. El espejo que forma paredes soñado por José Arcadio Buendía da un primer aviso de lo que será el sueño de los cuartos infinitos. Es una imagen cuya fuerza poética se incrementa al vincularse con el hielo (el funciona como piedra filosofal para descifrar el significado del sueño):

Una noche creyó encontrar una predicción sobre el futuro de Macondo. Sería una ciudad luminosa, con grandes casas de vidrio, donde no quedaba ningún rastro de la estirpe de las Buendía. «Es una equivocación -tronó José Arcadio Buendía-. No serán casas de vidrio sino de hielo, como yo lo soñé y siempre habrá un Buendía, por los siglos de los siglos (...)”. (54).

Las casas de espejos son recordadas como casas de hielo, material tan exótico en el trópico como el vidrio, pero parte de la identidad cíclica y eterna de los Buendía. En el anterior fragmento el protagonista opone el hielo a un cristal quizás premonitorio de la llegada de edificios modernos, pertenecientes a un tiempo histórico no deseado:

Cuando estaba solo, José Arcadio Buendía se consolaba con el sueño de los cuartos infinitos. Soñaba que se levantaba de la cama, abría la puerta y pasaba a otro cuarto igual, con la misma cama de cabecera de hierro forjado, el mismo sillón de mimbre y el mismo cuadrito de la Virgen de los Remedios en la pared del fondo. De ese cuarto pasaba a otro exactamente igual, cuya puerta abría para pasar a otro exactamente igual, y luego a otro exactamente igual, hasta el infinito. Le gustaba irse de cuarto en cuarto, como en una galería de espejos paralelos, hasta que Prudencio Aguilar le tocaba el hombro. Entonces regresaba de cuarto en cuarto, despertando hacia atrás, recorriendo el camino inverso, y encontraba a Prudencio Aguilar en el cuarto de la realidad. Pero una noche, dos semanas después de que lo llevaron a la cama, Prudencio Aguilar le tocó el hombro en un cuarto intermedio, y él se quedó allí para siempre, creyendo que era el cuarto real $(127)^{16}$.

La muerte del primer patriarca de la casa viene precedida de un sueño de cuartos sucesivos (conforme al esquema del eterno retorno que sufren los protagonistas) en un camino del que un día ya no regresa al encontrarse el protagonista con otro muerto.

El espacio y los objetos contenidos en él son elementos que participan igualmente del carácter de fábula mítica con la que el escritor envuelve la narración, en un hábil juego de acercamiento y alejamiento al realismo, lo que aleja no solo de la novela latinoamericana telúrica y costumbrista del siglo XIX sino de la escritura precisa y austera del autor que fue desde los años cincuenta. Un ejemplo de momento de incursión en un surrealismo primitivista es cuando una de las escasísimas ausencias de la casa de Úrsula da pie a que los objetos se comporten de manera extraña:

Un frasco vacío que durante mucho tiempo estuvo olvidado en un armario se hizo tan pesado que fue imposible moverlo. Una cazuela de agua colocada en la mesa de trabajo hirvió sin fuego durante media hora hasta evaporarse por completo. José Arcadio Buendía y su hijo observaban aquellos fenómenos con asustado alborozo, sin lograr explicárselos, pero interpretándolos como anuncios de la materia. Un día la canastilla de Amaranta empezó a moverse con un impulso propio y dio una vuelta completa en el cuarto, ante la consternación de Aureliano, que se apresuró a detenerla (38).

\footnotetext{
${ }^{16}$ Asimismo, Aureliano Buendía tiene su propio sueño recurrente de cuartos, vacíos y sin señales de presencia humana anterior (eco del sueño fundacional de un espacio pendiente de colonización); sueño que precede a su muerte. Soñó que entraba en una casa vacía, de paredes blancas, y que lo inquietaba la pesadumbre de ser el primer ser humano que entraba en ella. En el sueño recordó que había soñado lo mismo la noche anterior y en muchas noches de los últimos años (232).
} 
El cuarto de los santos, así llamado en la infancia de GGM en Aracataca, también contiene abundantes dosis de misterio, con esculturas de gran tamaño y ojos muy realistas que parecen observar a los niños que ahí dormían.

\section{El espacio histórico: la casa cerrada}

Tras habernos hecho conocer el universo doméstico mágico y autosuficiente de los Buendía el autor da un hachazo al aislamiento de Macondo con la llegada a la puerta de la casa de los primeros visitantes que no son gitanos (40), señal de la entrada a un orden histórico. Se trata de un aumento de población aún controlable por José Arcadio Buendía, quien impone un orden de trabajo y una licencia: la instalación de relojes musicales en las casas que sustituyen el canto de los pájaros liberados de sus jaulas las casas (41), transformación sonora que sustituye lo natural por lo mecánico, artificio que también veremos entrar en la casa con la incorporación de la pianola a la sala de visitas de los Buendía.

La novela se va poblando de nuevos personajes (el gobernador Moscote, el músico Pietro Crespi). Sentimos que nos adentramos en un tiempo moderno, que se caracteriza por la aceleración de su ritmo; se inicia la alfabetización que se sumará a la cultura oral, la religión oficializada, el tren y con él la compañía bananera, con lo que se hace necesaria la construcción de la iglesia, escuela, el barrio de los gringos. En la casa encontramos el taller de platería de Aureliano Buendía, una actividad productiva deudora de la alquimia que coexistirá como espacio de encierro masculino con el cuarto que Úrsula construye a Melquíades, depositario de la memoria escrita. Úrsula, para tratar de evitar la dispersión de hijos en edad de casarse, usa los ahorros producidos por la repostería y emprende la ampliación de la casa, de acuerdo, no sólo a unas necesidades reproductivas y productivas universales, sino a la idea de conveniencia y patrón de decoro social encarnada en las nuevas salas de estar y comedor:

Dispuso que se construyera una sala formal para las visitas, otra más cómoda y fresca para el uso diario, un comedor para una mesa de doce puestas donde se sentara la familia con todos sus invitados; nueve dormitorios con ventanas hacia el patio y un largo corredor protegido del resplandor del mediodía por un jardín de rosas, con un pasamanos para poner macetas de helechos y tiestos de begonias [...]. Seguida por docenas de albañiles y carpinteros, como si hubiera contraído la fiebre alucinante de su esposa, Úrsula ordenaba la posición de la luz y la conducta del calor, y repartía el espacio sin el menor sentido de sus límites (57).

Se trata de la descripción más extensa de la casa y se inspira en la vivienda que los abuelos de GGM ampliaron, en la que vivió sus primeros años, modificada por el recuerdo de una infancia donde el entorno circundante, como nos dice Bachelard parece "sin límites".

La remodelación descrita corresponde, a grandes rasgos, a la que dio lugar a la segunda casa de los abuelos de GGM, una casa de tres cuerpos (la oficina, la casa principal y el conjunto conformado por el cuarto de abuelos donde nació GGM, el cuarto de los santos y el los baúles, bacinillas y libros antiguos). Es interesante comparar el plano la casa natal anexado por D. Saldívar en las imágenes del Apéndice a su obra "Viaje a la semilla" con el plano que GGM dibujó en la entrevista con J. Gilard en Barcelona en 1978. En ambos planos destaca el gran comedor abierto al corredor de las begonias que articula la sucesión de las distintas estancias; en el primer tramo, a la derecha quedan el cuarto de visitas (así registrado por Saldívar, en el plano de Gilard figura como "oficina), el taller de platería y tras el comedor, una alcoba (nombrado como sala en Gilard; posiblemente una sala con funciones de alcoba), la alacena (granero en Gilard) y la cocina. Al final, el baño abierto, la alberca y el patio con el taller de carpintería (cuyo cartel fue colocado, en el plano de Girard de manera errónea al ponerlo más al frente) y un traspatio con el castaño que en dicho plano quedó integrado al patio, quizás por falta de espacio o por aquella unidad que produce el topoanálisis el espacio feliz recordado (Bachelard) ${ }^{17}$.

\footnotetext{
${ }^{17}$ La documentación visual de Saldívar incluye fotos del exterior de la casa original y una perspectiva axonométrica del inmueble. Es un plano del primer biógrafo de GGMM y el arq. Gustavo Castellón Licero, coautor de una tesis sobre la casa, firmado por el escritor (bajo la leyenda "consto que así fue").
} 


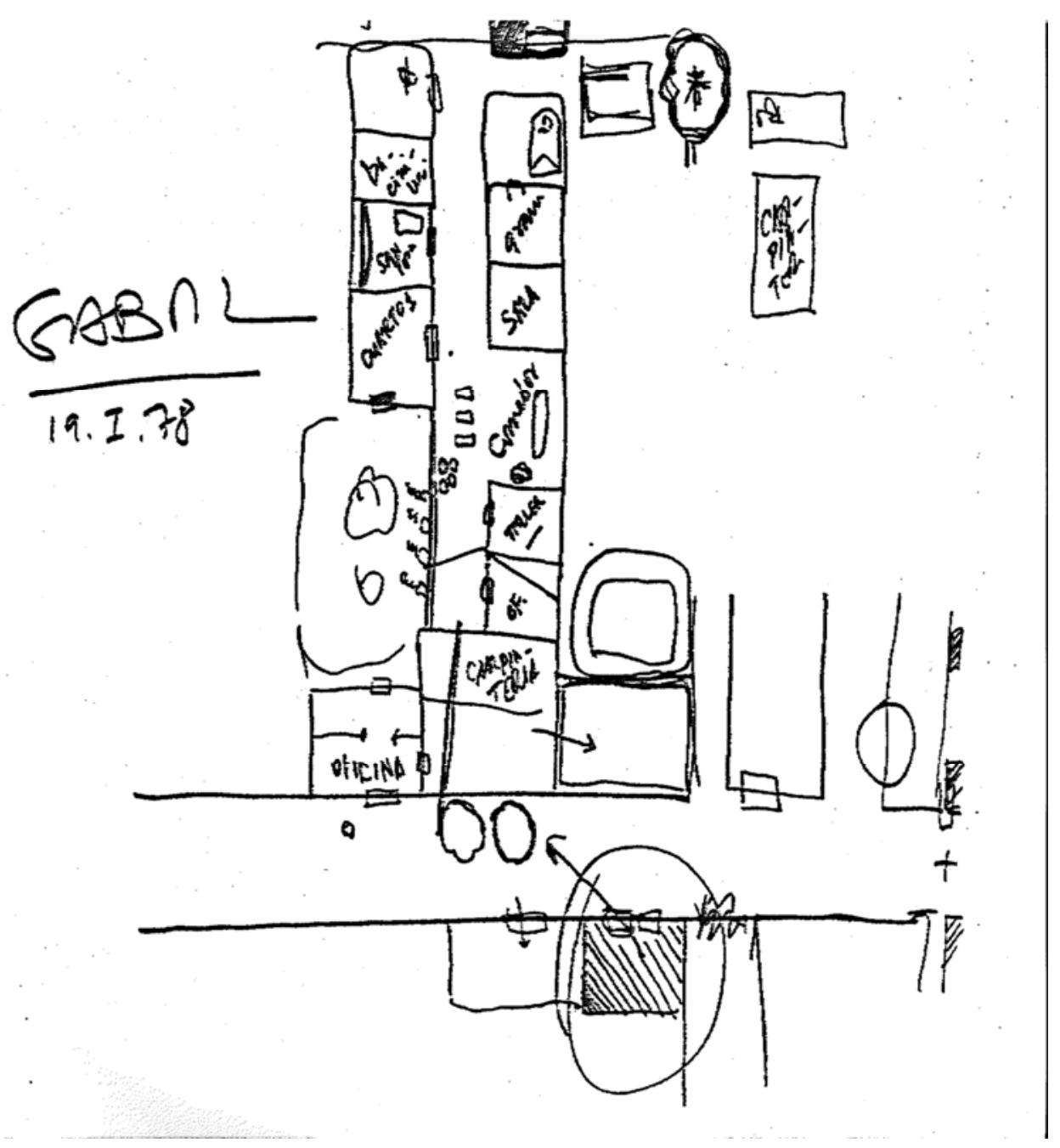

Fig. 1 Plano de la casa de Aracataca dibujado por el autor en Barcelona el 19 de enero de $1978^{18}$.

El crecimiento de la planta física doméstica del hogar de los Buendía va acompañado de un nuevo refinamiento de las costumbres (se inaugura con un baile, 59), un esmero en la decoración pensada para que Rebeca y Amaranta tengan "un lugar digno donde recibir las visitas" (59). A la sala y comedor llega no sólo la pianola sino también "muebles vieneses, la cristalería de Bohemia, la vajilla de la Compañía de las Indias, los manteles de Holanda y una rica variedad de lámparas y palmatorias, y floreros, paramentos y tapices", así como lámparas de alquitrán. Es decir, estamos ante un interior influido por el modelo occidental-colonial basado en el consumo conspicuo y la acumulación de objetos que visten un espacio doméstico y privado, cuyo confort e intimidad se vinculan a un uso primordialmente familiar de la casa, con una vida social acotada tal como ha sido historiada por Ph. Ariès y W. Rybsvzynsi.

La nueva elegancia de la casa no substituye, sino que se superpone al espíritu de la casa tradicional. Esto queda sugerido más adelante, cuando leemos sobre un regreso épico de José Arcadio: Fue directamente a la cocina, y allí se paró por primera vez en el término de un viaje que había empezado al otro lado del mundo. La cocina, equivalente al thalamos (dormitorio) al que regresa Ulises en Itaca y que debe reconocer para probar su identidad sigue siendo el corazón ancestral de la casa: lugar de reproducción de la vida, pero también de producción, el corazón de la vivienda, donde se comerá hasta que Fernanda prohíba ahí dicha práctica y la traslade al comedor, espacio formal que da un estatus burgués a la familia.

A pesar de la visible hostilidad la familia, Fernanda no renunció a la voluntad de imponer los hábitos de sus mayores. Terminó con la costumbre de comer en la cocina, y cuando cada quien tenía hambre, e impuso 
la obligación de hacerlo a horas exactas en la mesa grande del comedor arreglada con manteles de lino, y con los candelabros y el servicio de plata:

La solemnidad de un acto que Úrsula había considerado siempre como el más sencillo de la vida cotidiana creó un ambiente de estiramiento contra el cual se reveló primero que nadie el callado José Arcadio Segundo (186).

Fernanda también ordena el cierre de la casa hacia sí misma, en un gesto burgués de búsqueda de intimidad y privacidad doméstica que rompe con la anterior apertura hospitalaria y tradicional, percibida como promiscua ("dentro y fuera constituyen una dialéctica de descuartizamiento", Bachelard 2000: 185):

Las puertas de la casa, abiertas de par en par desde el amanecer hasta la hora de acostarse, fueron cerradas durante la siesta, con el pretexto de que el sol recalentaba los dormitorios, y finalmente se cerraron para siempre" (187) [...]. Nadie había vuelto a asomarse a la calle. Si de Fernanda hubiera dependido no habrían vuelto a hacerlo jamás, no sólo desde que empezó a llover, sino desde mucho antes (277). [...] ella consideraba que las puertas se habían inventado para cerrarlas, y que la curiosidad por lo que ocurría en la calle era cosa de rameras (277).

Durante los primeros años de Macondo, por el contrario, la casa había sido un lugar abierto a celebrar actos públicos como la boda entre Aureliano Buendía y Remedios Moscote (ante un altar colocado en la sala de visitas) y el bordado con las amigas en el corredor de las begonias. Siempre atentos a la llegada de los forasteros, la servidumbre se mostraba presta a preparar comida y cama. Úrsula identificaba vitalidad y auge doméstico con el movimiento, generosidad y prestigio derivado de la recepción de gente externa al núcleo doméstico. Ya en sus años de decadencia, viendo los derroteros por los que se dirigía su nuera...:

Úrsula trataba de ir siempre más lejos. «Que abran puertas y ventanas -gritaba-. Que hagan carne y pescado, que compren las tortugas más grandes, que vengan los forasteros a tender sus petates en los rincones y a orinarse en los rosales, que se sienten a la mesa a comer cuantas veces quieran, y que eructen y despotriquen y lo embarren todo con sus botas, y que hagan con nosotros lo que les dé la gana, porque esa es la única manera de espantar la ruina. (292)

Úrsula anticipa un aislamiento endogámico que a la larga provocará que se cumpla la maldición inicial con la que la familia tiene que cargar. Antes de morir reza para evitar que la ruina se apodere de la familia y da consejos para mantener a raya a las hormigas coloradas, para no dejar que se apague la lámpara en el cuarto de Remedios y que ni "ningún Buendía fuera a casarse con alguien de su misma sangre, porque nacían los hijos con cola de puerco" (296). La maldición se cumple. Pero la evolución hacia el apocalipsis final de Macondo de Cien años de soledad no es lineal. En el transcurso de la novela presenciamos varios ciclos de reconstrucción y ruina doméstica $(161,298)$, concomitantes a las distintas plagas que acechan Macondo (donde se expresa un tiempo mítico) y desgastan la capacidad de sobrevivir de la aldea. A la muerte de Úrsula, la casa volvió a caer en un abandono del cual no la podría rescatar ni siquiera una voluntad tan resuelta y vigorosa como la de Amaranta Úrsula, que muchos años después, siendo una mujer sin prejuicios, alegre y moderna, con los pies bien asentados en el mundo, abrió puertas y ventanas para espantar la ruina, restauró el jardín, exterminó las hormigas coloradas que ya andaban a pleno día por el corredor, y trató inútilmente de despertar el olvidado espíritu de hospitalidad (301). Un golpe importante a la resiliencia de la casa es la marcha de Santa Sofía, desanimada por "la imposibilidad de recuperar el decoro del cuarto de Melquíades, [...] así lo barriera y sacudiera tres veces al día [...] -Me rindo -le dijo a Aureliano-. Ésta es mucha casa para mis pobres huesos" (312).

De la casa mítica, sencilla pero sólida hemos pasado a una casa histórica, excesiva, que se dirige hacia la decadencia. La plaga de la modernidad ya no es una plaga mítica (como la del olvido o la del diluvio). Es un desorden provocado por el hombre (aquí GGM anticipa las teorías del cambio climático) con una compañía bananera que rompe con el equilibrio natural del entorno, lleva al espacio a una destrucción profetizada en la narración de los pergaminos. La última resurrección, protagonizada por Amaranta Úrsula es ya sólo un 
remedo de lo inevitable, un último esfuerzo romántico por preservar un nido amoroso (un último paraíso simétrico al paraíso inicial) donde el éxtasis incestuoso corre parejo a la destrucción del entorno. La historia de los Buendía se apuntala en un eje sobre el que giran los círculos concéntricos que se va desgastando, haciendo imposible el eterno retorno mítico. Por ello la figura de una espiral tridimensional, cónica e invertida, me parece más indicada que la del círculo para representar gráficamente la novela ${ }^{19}$. Ésta se presenta como una narración lineal (la visión apocalíptica judeo-cristiana es lineal, apunta Palencia-Roth; "no habrá una segunda oportunidad en la tierra" leemos en el final del libro), pero no tarda en mostrar elementos circulares, cíclicos. Los hechos van girando en espiral sobre sí mismos, pero en un movimiento cada vez más estrecho, con una progresiva clausura espacial de la casa respecto al exterior que, a mi juicio, es elemento esencial en la decadencia progresiva y a la vez condición para la lucidez individual final. El libro terminará como empezó, sin Macondo, de ahí el carácter circular que los analistas atribuyen a la novela. Sin embargo, inicio y fin no son idénticos; el libro arranca en un espacio exterior (la aldea feliz y su entorno) y termina en uno interior (un cuarto y dentro de él, otro espacio más interior, el simbólico contenido en la escritura) desde el cual se obtienen una visión de la profecía sobre el exterior (visión que será un regreso momentáneo a la visión de la eternidad mítica). El último reducto espacial es así un espacio cerrado, de creación y memoria, como el que vive el mismo GGM, lo que nos lleva a calificarlo de biográfico.

\section{El espacio biográfico: el cuarto de Melquíades}

El cuarto de Melquíades es uno de los espacios que resisten más tiempo los embates de la decadencia (junto al taller de platería y las habitaciones de Santa Sofía), lo que posibilita el desciframiento de las profecías de los pergaminos contenidos en él, la lectura de lo que el lector ya ha leído. Aureliano Segundo es un espejo de GGM; descifra la historia que es el libro que de hecho está escribiendo (también en un espacio cerrado) el propio GGM:

El resto de la casa se rindió al asedio tenaz de la destrucción. El taller de platería, el cuarto de Melquíades, los reinos primitivos y silenciosos de Santa Sofía de la Piedad quedaron en el fondo de una selva doméstica que nadie hubiera tenido la temeridad de desentrañar. (354)

La historia de este espacio arranca cuando, en la gran remodelación de la casa, Úrsula lo manda a construir para el ya muy viejo Melquíades, quien prácticamente no saldrá de él. Después de su muerte, el lugar sufre un destino ambivalente. Por un lado, síntoma de abandono, queda reconvertido y renombrado (228) como cuarto de las bacinillas (correspondiente al cuarto del mismo nombre de la casa de Aracataca), con lo que hay una yuxtaposición de lo más bajo y lo más alto similar al castaño del patio (donde Aureliano Buendía orina antes de morir). Por otro sigue siendo el refugio espiritual (en un momento es inmune al polvo, como lugar eterno, contraparte del cuarto de los santos), un resto del espacio mítico en el espacio histórico; espacio de salvación de José Arcadio Segundo (en el momento en que lo buscan los militares por la huelga de los obreros (270) y de iniciación. Allí, con el candado puesto en la puerta, José Arcadio Segundo repasa en soledad los manuscritos de Melquíades (Santa Sofía le deja preparada la comida en el alfeizar de la ventana, 272). Cuando se le une Aureliano Segundo:

[...] ambos recordaban la visión atávica de un anciano con sombrero de alas de cuervo que hablaba del mundo a espaldas de la ventana, muchos años antes de que ellos nacieran. Ambos descubrieron al mismo tiempo que allí siempre era marzo y siempre era lunes, y entonces comprendieron que José Arcadio Buendía no estaba tan loco como contaba la familia, sino que era el único que había dispuesto de bastante lucidez para vislumbrar la verdad de que también el tiempo sufría tropiezos y accidentes, y podía por tanto astillarse y dejar en un cuarto una fracción eternizada. (303)

En las últimas páginas se filtran referencias muy claras de la vida del propio GGM (inclusión que recuerda a los retratos de los amigos de Diego Rivero en los murales): su esposa con el mismo nombre, el sabio catalán, sus colegas... Aureliano Babilonia, como el escritor, queda atrapado por el embrujo de

\footnotetext{
${ }^{19}$ Vargas Llosa menciona la figura de espiral de círculos concéntricos (1969: 144) en un sentido distinto al que aquí uso: para referirse a una sucesión de tres planos narrativos (la familia, el pueblo, América y la Humanidad).
} 
"adivinar el mundo", descifrando los pergaminos y en el cuarto de Melquíades tiene la revelación de la profecía:

Sin embargo, antes de llegar al verso final ya había comprendido que no saldría jamás de ese cuarto, pues estaba previsto que la ciudad de los espejos (o los espejismos) sería arrasada por el viento y desterrada de la memoria de los hombres en el instante en que Aureliano Babilonia acabara de descifrar los pergaminos [...].

La analogía del cuarto de Melquíades con el espacio físico del escritor que está escribiendo lo que leemos, es decir con el espacio del propio GGM, está latente en un emocionante final donde tiempo mítico (el destino ineludible por un pecado original), tiempo histórico (el fracaso de la voluntad humana borrada por el huracán bíblico) y tiempo biográfico (la narración de un escritor que adivina el mundo) se funden. Gerald Martin (2009: 341) dice que no es extraño que GGM se sintiera como un alquimista, mezclando a Faulkner con Nostradamus y Borges en su cuarto de la casa de San Ángel en la Ciudad de México donde también recibía visitas. Los amigos de GGM llamaban al man cave de GGM la Cueva de la Mafia, o también cuarto de Melquíades.

El aislamiento de la casa (espacio histórico), paralelo al aislamiento de los varones Buendía en el cuarto de la escritura (espacio biográfico) ha comportado la ruina por soledad y falta de amor; paradójicamente dicha soledad es necesaria para descifrar la historia (y para escribir la novela) ${ }^{20}$. Es revelador que sea un Aureliano el último habitante de la casa. Sin la mujer, el espacio desaparece; "creo que las mujeres sostienen el mundo en vilo, para que no se desbarate mientras los hombres tratan de empujar la historia (Mendoza, García Márquez 1982: 30, 98). En una cueva masculina que funciona como la concha-nido de Bachelard, donde se termina la búsqueda prometeica del sentido de la historia, búsqueda absurda que ha comportado fatalmente una destrucción centrípeta espacial y del matriarcado que acaba siendo también el fin de la historia empujada por los hombres.

El espacio biográfico es contiene elementos míticos pues es en esta última estancia (anticipada por el último cuarto de los sueños de los Buendía) donde el lector (Aureliano Babilonia y el propio lector de Cien años de soledad) experimentan un punto de epifanía (N. Frye, citado en Palencia-Roth 1983: 128), concepto vinculado al de imagen cósmica (Bachelard señala que es una imagen recurrente en la infancia). El escritorlector se sustrae ahí del tiempo lineal, no tanto en un regreso circular hacia el inicio, sino para conectar con un tiempo eterno. El punto de epifanía es un tiempo en el que están todos los tiempos; los pergaminos existen en un presente eterno, como la novela, y en el momento del punto de epifanía se encuentran alienados el mundo apocalíptico (lineal) y el mundo cíclico, por lo que se forma una espiral.

Así, podemos concluir que del espacio mítico hemos pasado a un espacio histórico que se ha desgastado por su misma clausura y ha reducido el exterior a interior, conduciéndonos al espacio biográfico. El final de Cien años de soledad tiene una magia especial por el tono y ritmo de la prosa, con frases muy largas que parecen reflejar el esfuerzo titánico de GGM por culminar la obra enfrentándose a las obsesiones dominantes de su vida. Entre dichas obsesionas está la de conocer el límite de sus capacidades, saber si puede acabar la gran novela largamente anhelada y ser el escritor profesional libre de deudas económicas, inventándose a sí mismo como el gran escritor-mago más allá del neorrealismo de la posguerra y conectar con las grandes preguntas humanas. Ello le requería entenderse a sí mismo, así como gestionar emocionalmente y rescatar del olvido la casa y su vida (viajar del presente a un presente eterno). La escritura transfigura poéticamente un pasado turbulento, una infancia atípica (una educación apartada de los padres biológicos, y un duelo pendiente por la muerte de los abuelos) ${ }^{21}$ pero hermosa, creadora de poderosas imágenes. Para GGM "toda buena novela es una adivinación del mundo" (Durán 1968: 28). La novela funciona como una adivinación del mundo, un desciframiento de sus claves (el espacio y el tiempo que lo articulan) a través del recuerdo

${ }^{20}$ GGM hizo construir una puerta en su cuarto de la CDMX para aislarse mejor de la casa y poder escribir la novela, según se comenta en: https://www.youtube.com/watch?v=gkhqAbrUMNM

${ }^{21}$ Cuenta GGM a A. Mendoza (1982: 23): "El distintivo de mi relación con mi madre, desde muy niño, ha sido la seriedad. Es tal vez la relación más seria que he tenido en mi vida, y creo que ella y yo no podamos decirnos ni ningún tema que no podamos tratar, pero casi siempre lo hemos hecho, más que con un sentido de intimidad, con un cierto rigor que casi podría considerarse profesional". Sobre la muerte del abuelo Nicolás, cuenta en la misma entrevista (20-21): No lo vi morir, porque yo estaba en otro pueblo por esos días, lejos de Aracataca y ni siquiera me dieron la noticia de modo directo, sino que la oí comentar en la casa en la que estaba. Recuerdo que no me causó ninguna impresión. Pero en toda mi vida de adulto, cada vez que me ocurre algo, sobre todo cada vez que me sucede algo bueno, siento que lo único que me falta para que la alegría sea completa, es que lo sepa el abuelo". 
poético. Aureliano Buendía recuerda la tarde en que su padre lo llevó a conocer el hielo como GGM recuerda la casa de su abuelo que lo llevaba al circo. El hielo (lo efímero, lo desconocido, en definitiva, el mundo) pudiera ser en realidad la piedra filosofal de Aureliano Buendía como lo pudo ser para GGM la primera frase de la novela que lo encumbró.

\section{Referencias bibliográficas}

Arnau, Carmen (1975). El mundo mítico de Gabriel García Márquez. Barcelona: Península.

Bachelard, Gastón (2000). La poética del espacio. México: FCE.

Cassá, Roberto (1974). Los taínos de la Española. Santo Domingo: Universidad Autónoma de Santo Domingo.

Collazos, Oscar (1983). García Márquez. La soledad y la gloria. Barcelona: Plaza y Janés.

Durán, Armando (1968), “Conversaciones con García Márquez”, Revista Nacional de Cultura (Caracas), (1968), 29, n 185, p. 28.

Fernández, Dominique (1981), "Introducción a la psicobiografía", en D. Sallenave (comp.). Psicoanálisis y Crítica Literaria. Madrid: Akal.

García Márquez, Gabriel y Mario Vargas Llosa (1967). La novela en América Latina. Lima: Batres-Universidad Nacional de Ingeniería.

García Márquez, Eligio (2001). Tras las claves de Melquíades. Bogotá: Ed. Norma.

García Márquez, Gabriel (1972). Cien años de soledad. Buenos Aires: Ed. Latinoamericana.

García Márquez, Gabriel (2002). Vivir para contarla. Bogotá: Ed.Norma.

Illich, I. (1990). El género vernáculo. México: Joaquín Mortiz.

Ludmer, Josefina (1985). Cien años de soledad: una interpretación. Buenos Aires: Centro Editor de América Latina.

Martin, Gerald (2009). García Márquez, una vida. Madrid: Vintage-Random Hose.

Maturo, Graciela (1973). Claves simbólicas de García Márquez. Buenos Aires: Fernando García Cambeiro.

Mendoza, Plinio A. y G. García Márquez (2000). Aquellos tiempos con Gabo. Barcelona: Plaza \&Janés.

Morán Garay, Diana (1988). Cien años de soledad: novela de la desmitificación. México: UAM.

Noujoumian, Amir (2006), "Poetization of Space in One Hundred Years of Solitude", Pazhuhesh-e Zabanha-ye Khareji, $\mathrm{n}^{\circ} 27$ (2006), Special Issue, English, pp. 41-51.

Palencia-Roth, Michael (1983). Gabriel García Márquez. La línea, el círculo y las metamorfosis del mito. Madrid: Gredos.

Pané, Fray Ramón (1988). Relación acerca de las antigüedades de los indios. México: Siglo XXI.

Salazar Ramírez, Bernardo (1983). García Márquez: su mensaje. Medellín: Ealon.

Saldivar, Lasso (1997). García Márquez: viaje a la semilla. Madrid: Alfaguara.

Saldivar, Lasso (2016), "Aquí nació Gabo", Abc. Cultural, 9 de marzo de 2016. Disponible en: http://www.abc.es/cultura/cultural/abci-aqui-nacio-gabo-201603091954 noticia.html

Sanabria, Fabián (2012), "La Poética del Espacio recreada en la casa Gabriel García Márquez", en Alexander Stip Martínez (ed.). Imaginación, subjetividad, saber. Memorias del Simposio Internacional Imaginación, Subjetividad, Saber. Bachelard: 50 años. Agosto-Noviembre 2012, pp. 111-118.

Spurr, David (2012). Architecture and Modern Literature. Michigan: The University of Michigan Press.

Tuna Ultav, Zeynep et al. (2015), “Architectural literary analysis: Reading 'the death of the Street"throught Ballard's literature and Trancik's lost space", Metu, Journal of the Faculty of Architecture, 32: 2, pp.133-150.

Vargas Llosa, Mario (1971). García Márquez, historia de un deicidio. Barcelona: Barral.

Vargas Llosa. Mario (1976), "Cien años de soledad, el Amadís de América”, Amaru, nº 3 (1976).

Vargas Llosa, Mario (1969), "García Márquez. De Aracataca a Macondo", en Mario Benedetti et.al. Nueve asedios a García Márquez. Santiago de Chile: Ed. Universitaria.

Volkening, Ernesto (1998). Gabriel García Márquez. Un triunfo sobre el olvido. Bogotá: Arango editores.

Williams, Raymond (2010). A companion to Gabriel García Márquez. Nueva York: Tamesis. 